\title{
A Dynamic Reciprocal Dumping Model of International Trade
}

\author{
Kenji Fujiwara $^{a^{*}}$
}

${ }^{a}$ Kwansei Gakuin University

\begin{abstract}
This paper constructs a differential game model of reciprocal dumping to reconsider the welfare effects of trade liberalization (tariff reductions). We show that welfare in autarky exceeds welfare in trade for any tariff level, namely that any trade is detrimental. Comparing our result with a static result, we discuss that the closed-loop property of feedback strategies in differential games plays a significant role in our argument.
\end{abstract}

JEL Classifications: C73, F12

Keywords: differential game, trade liberalization, losses from trade, dynamic duopoly

\section{Introduction}

While multilateral trade liberalization has greatly progressed over the last 50 years, there has been persistent resistance to globalization. One of the tasks of international economics is to make clear why such anti-globalization remains, despite the fact that the fruits of globalization are spreading around the world. We can find some literature answering this concern by showing a possibility of Pareto inferior trade, i.e. all countries lose from trade. Typical examples include Kemp and Long (1979) and Tran-Nam (1985) in a context of overlapping generations and Newbery and Stiglitz (1984) and Shy (1988) under market incompleteness. ${ }^{1}$

This paper seeks another source of Pareto inferior trade and anti-globalization in an oligopolistic context. For this purpose, we extend Benchekroun's (2003) dynamic duopoly model to international trade engaged by home and foreign firms like Brander

\footnotetext{
* Corresponding author: School of Economics, Kwansei Gakuin University, Uegahara 1-1-155, Nishinomiya, Hyogo, 662-8501, Japan. Tel: +81-798-54-7066. Fax: +81-798-51-0944. E-mail: kenjifujiwara@ kwansei.ac.jp. I thank Hong Hwang, Ngo Van Long, Chia-Hui Lu, Eden Yu, an anonymous referee and participants at the 2009 APJAE Symposium on Trade, Environment and Resource for helpful comments. Any remaining errors are my own responsibility.

${ }^{1}$ It is known that there is a scheme of income redistribution which makes every agent gain from trade even under overlapping generations and market incompleteness. See Kemp (1995) and Wong (1995) for details.
} 
(1981), Brander and Krugman (1983), Brander and Spencer (1984) and Helpman and Krugman (1985). ${ }^{2}$ The resource is assumed to be a common property and to be renewable. We will prove that steady state welfare under autarky is larger than steady state welfare under trade for any positive tariff, namely, trade necessarily reduces steady state welfare as compared to autarky. It is discussed that the closed-loop property of feedback strategies plays a crucial role behind our result, which sharply contrasts to the static result. ${ }^{3}$

This paper is planned as follows. Section 2 presents a model and Section 3 characterizes the steady state in the feedback Nash equilibrium. Section 4 states and discusses our main result. Section 5 concludes the paper. Appendices provide a formal proof of the losses-from-trade proposition.

\section{A Model}

The model is a combination of Benchekroun's (2003) dynamic duopoly model and a reciprocal dumping model of Brander (1981), Brander and Krugman (1983), Brander and Spencer (1984), and Helpman and Krugman (1985). Suppose there are two symmetric countries (Home and Foreign), two goods (Goods 1 and 2) and one factor (labor). All the Foreign variables are asterisked. Good 1 is a non-numeraire good and Good 2 a numeraire good both of which are produced from labor. Without loss of generality, one unit of labor produces one unit of Good 2 so that the wage rate is fixed to unity. Production of Good 1, which is nationally monopolized, incurs a constant marginal cost $c \geq 0$ and exports are subject to a specific tariff $\tau{ }^{4}$ Letting $x$ (resp. $y$ ) and $x^{*}$ (resp. $y^{*}$ ) denote the supply into the Home market and the Foreign market by the Home (resp. Foreign) firm, demand is given by a linear function: $p=a-x-y, p^{*}=a-x^{*}-y^{*}, a>c$, where $p$ and $p^{*}$ are the relative price of Good 1 in the Home and Foreign markets, respectively. ${ }^{5}$

In supplying Good 1, a country-specific stock of a renewable resource $S$ and $S^{*}$ is exploited. ${ }^{6}$ We assume the following resource dynamics: ${ }^{7}$

$$
\begin{aligned}
& \dot{S}=k S-x-y \\
& \dot{S}^{*}=k S^{*}-x^{*}-y^{*},
\end{aligned}
$$

\footnotetext{
${ }^{2}$ Benchekroun (2003) assumes symmetric duopoly under which both firms have the identical cost. Benchekroun (2008) extends this model to accommodate an arbitrary number of firms and prove some counter-intuitive results.

${ }^{3}$ See, among others, Markusen (1981), Brander (1981), Brander and Krugman (1983), and Helpman and Krugman (1985).

${ }^{4}$ It is possible to interpret $\tau$ as a transport cost rather than a tariff. Fujiwara (2009) deals with the case of transport costs.

${ }^{5}$ We exclusively focus on the equilibrium in Home since Foreign is a mirror image of Home.

${ }^{6}$ It is assumed that resources are local. The case of transboundary resources like Benchekroun and Long (2002) is beyond the scope of this paper while it is worth trying.

${ }^{7}$ Benchekroun $(2003,2008)$ uses more general dynamics of resource by allowing for the possibility that the natural growth $k S$ becomes negative if $S$ is sufficiently large.
} 
where $k$ is a natural rate of resource growth. Under these assumptions and constraint (1), each firm maximizes a discounted sum of profits:

$$
\begin{aligned}
& \int_{0}^{\infty} e^{-r t}\left[(a-c-x-y) x+\left(a-c-\tau-x^{*}-y^{*}\right) x^{*}\right] d t \\
& \int_{0}^{\infty} e^{-r t}\left[(a-c-\tau-x-y) y+\left(a-c-x^{*}-y^{*}\right) y^{*}\right] d t
\end{aligned}
$$

where $r \geq 0$ is a constant rate of discount.

\section{Feedback Nash equilibria}

This section derives a (linear) feedback Nash equilibrium of the above dynamic game. ${ }^{8}$ To this end, set up the Home firm's Hamilton-Jacobi-Bellman equation:

$$
r V\left(S, S^{*}\right)=\max _{x, x^{*}}\left\{\begin{array}{l}
{\left[a-c-x-y\left(S, S^{*}\right)\right] x+\left[a-c-\tau-x^{*}-y\left(S, S^{*}\right)\right] x^{*}} \\
+V_{S}\left(S, S^{*}\right)\left[k S-x-y\left(S, S^{*}\right)\right]+V_{S^{*}}\left(S, S^{*}\right)\left[k S^{*}-x^{*}-y^{*}\left(S, S^{*}\right)\right]
\end{array}\right\},
$$

where $V\left(S, S^{*}\right)$ is a value function of the Home firm and, $V_{S}(\cdot)$ and $V_{S^{*}}(\cdot)$ are the partial derivative.

Suppose that each firm's strategy is linear in the state variables. As is proved in Appendix A, the Home firm's equilibrium outputs are obtained as $x=\alpha S+\beta$ and $x^{*}=\alpha S^{*}+\beta^{*}$, where

$$
\begin{aligned}
& \alpha=0, \frac{6 k-3 r}{8} . \\
& \beta=\frac{[(k-r)(a-c)-(4 \alpha-k+r) \tau](\alpha-k+r)}{(k-r)(8 \alpha-3 k+3 r)} \\
& \beta^{*}=\frac{[(k-r)(a-c)+(4 \alpha-2 k+2 r) \tau](\alpha-k+r)}{(k-r)(8 \alpha-3 k+3 r)} .
\end{aligned}
$$

Similarly, the Foreign firm's outputs are $y=\alpha S+\beta^{*}$ and $y^{*}=\alpha S^{*}+\beta$.

Two points deserve attention. First, we see that $x$ (resp. $\left.x^{*}\right)$ and $y^{*}($ resp. $y)$ have the same functional form, i.e., $x=\alpha S+\beta$ and $y^{*}=\alpha S^{*}+\beta$ because the two countries are identical in all respects and feedback strategies are separable in $S$ and $S^{*}$. Therefore, we

\footnotetext{
${ }^{8}$ The derivation technique here follows Tsutsui and Mino (1990), Shimomura (1991) and Dockner and Long (1993). See also Dockner et al. (2000).
} 
will exclusively restrict attention to the Home market. Second, $\alpha=0$ corresponds to static Cournot outputs since $\alpha=0$ leads to

$$
x=y^{*}=\frac{a-c+\tau}{3}, x^{*}=y=\frac{a-c-2 \tau}{3} .
$$

On the other hand, substituting $\alpha=(6 k-3 r) / 8$ into (5), we obtain

$$
\begin{aligned}
& \beta=\frac{-(2 k-5 r)[2(k-r)(a-c)-(4 k-r) \tau]}{48 k(k-r)} \\
& \beta^{*}=\frac{-(2 k-5 r)[2(k-r)(a-c)+(2 k-r) \tau]}{48 k(k-r)} .
\end{aligned}
$$

Henceforth, we make a technical assumption to facilitate analysis. ${ }^{9}$

Assumption $2 k-5 r>0$.

Roughly speaking, this assumption requires the renewable property of the resource be significantly relevant. Utilizing (4) and (6), we proceed to characterize the feedback strategies of each firm. Setting $\alpha S+\beta^{*}=0$, the export is zero if $S$ is so small that $S<-\beta^{*} / \alpha$. In the other extreme case, the export is given by the static one $x^{*}=(a-c-2 \tau) / 3$ if $S$ becomes large enough to have $S \geq\left(a-c+\tau-3 \beta^{*}\right) / 3 \alpha$ by setting $\alpha S+\beta^{*}=(a-c-2 \tau) / 3$. What is further noted is that the domestic supply exhibits jumps at these two thresholds of $S^{10}$. This is because the supply into the domestic market switches at $S=-\beta^{*} / \alpha$ and $S=\left(a-c+\tau-3 \beta^{*}\right) / 3 \alpha$. In view of these and using the approach in Benchekroun $(2003,2008)$ and Lohoues (2006), the following results can be obtained.

$$
\begin{aligned}
& x(S)= \begin{cases}0 & \text { if } S<\frac{-\beta^{*}}{\alpha} \\
\alpha S+\beta & \text { if } \frac{-\beta^{*}}{\alpha} \leq S \leq \frac{a-c+\tau-3 \beta^{*}}{3 \alpha} \\
\frac{a-c+\tau}{3} & \text { if } S>\frac{a-c+\tau-3 \beta^{*}}{3 \alpha}\end{cases} \\
& y(S)= \begin{cases}0 & \text { if } S<\frac{-\beta^{*}}{\alpha} \\
\alpha S+\beta^{*} & \text { if } \frac{-\beta^{*}}{\alpha} \leq S \leq \frac{a-c-2 \tau-3 \beta^{*}}{3 \alpha} \\
\frac{a-c-2 \tau}{3} & \text { if } S>\frac{a-c-2 \tau-3 \beta^{*}}{3 \alpha}\end{cases}
\end{aligned}
$$

\footnotetext{
${ }^{9}$ Benchekroun $(2003,2008)$ also makes the same assumption.

${ }^{10}$ See Lohoues (2006) for more details.
} 


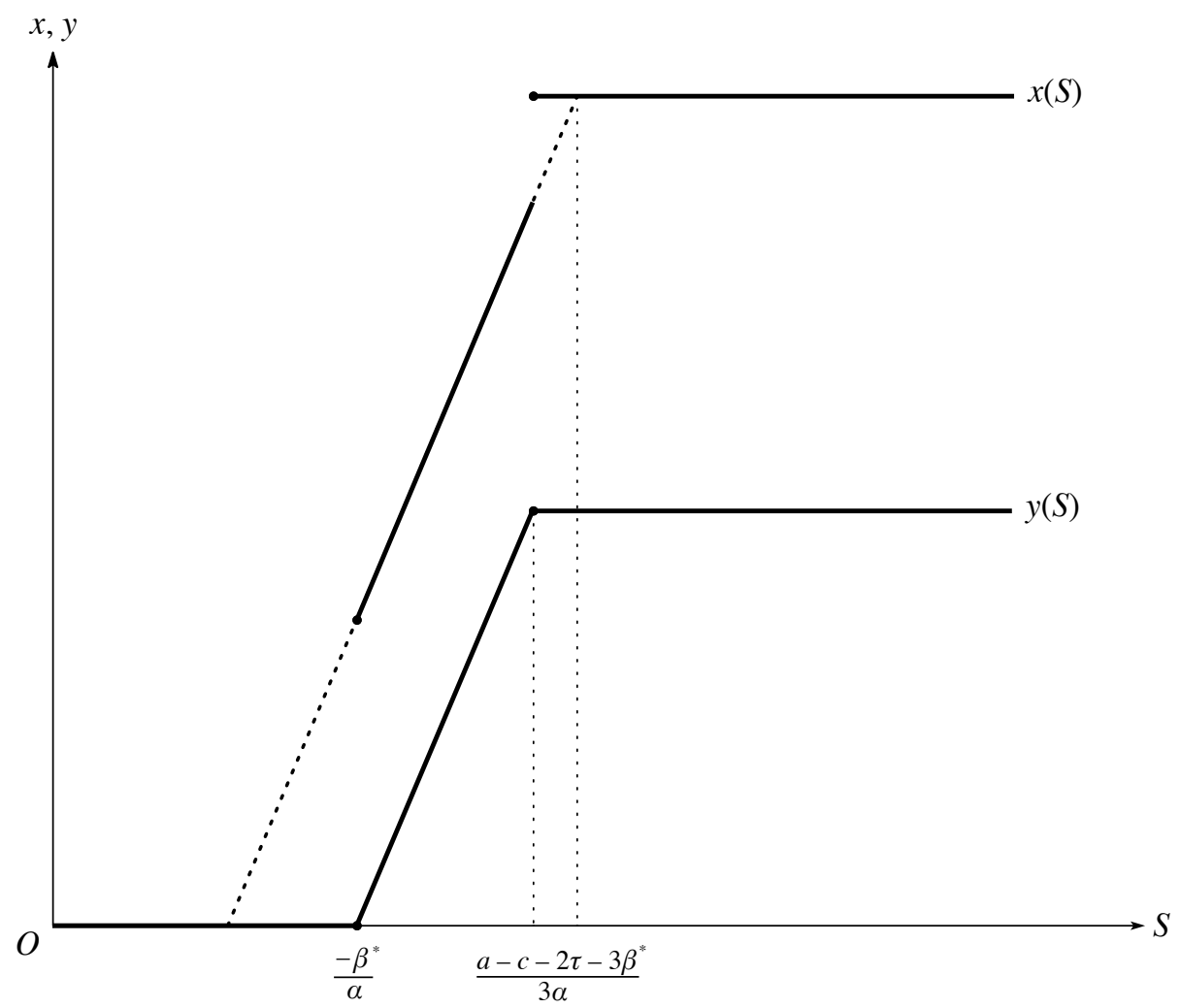

Figure 1: Feedback strategies

Eq. (7) can be interpreted diagrammatically as illustrated in Figure 1. It states that static Cournot outputs cannot be sustained for ever unless $S$ is sufficiently large. Depending on parameters, there can be multiple steady states but we are interested only in the steady state where supplies are increasing in $S$ since the case with static Cournot outputs contains nothing new. ${ }^{11}$

\section{Effects of Trade Liberalization}

Based on the results in the last section, we turn to the welfare effects of trade liberalization, i.e. an exogenous reduction in $\tau$. For this purpose, let us define a welfare function. Since it is extremely difficult to obtain lifetime welfare, we consider only the steady state. The symmetry between countries allows us to restrict attention to Home's

${ }^{11}$ Moreover, the steady state under static Cournot outputs is asymptotically unstable. Hence, it would be fair to focus on the case in which outputs are increasing in $S$. 
welfare, which is composed of consumer surplus, the Home firm's profit and tariff revenue:

$$
\begin{aligned}
& W=\int_{0}^{x+y}(a-X) d X-p \cdot(x+y)+(p-c) x+\left(p^{*}-c-\tau\right) x^{*}+\tau y \\
& =\frac{(x+y)^{2}}{2}+(a-c-x-y) x+\left(a-c-\tau-x^{*}-y^{*}\right) x^{*}+\tau y .
\end{aligned}
$$

In the steady state associated with $x=\alpha S+\beta$ and $y=\alpha S+\beta^{*}$, the steady state stock of $S$ satisfies $\dot{S}=k S-\alpha S-\beta-\alpha S-\beta^{*}=0$, from which we have $S=\left(\beta+\beta^{*}\right) /(k-2 \alpha)$. Substituting this into (7) and considering the symmetry between countries, the steady state supply into the domestic market and export are respectively obtained as

$$
x=y^{*}=\frac{\alpha\left(\beta+\beta^{*}\right)+\beta(k-2 \alpha)}{k-2 \alpha}, x^{*}=y=\frac{\alpha\left(\beta+\beta^{*}\right)+\beta^{*}(k-2 \alpha)}{k-2 \alpha} .
$$

Substituting these into (8), using (4) and (6), and rearranging terms, steady state welfare in the asymptotically stable feedback Nash equilibrium is explicitly computed as follows. $^{12}$

$$
W(\tau)=\frac{(2 k-5 r)\left[-(2 k-5 r) \tau^{2}-16(k-r)(a-c) \tau+4(10 k-13 r)(a-c)^{2}\right]}{72(2 k-3 r)^{2}}
$$

The rest of our task is to closely examine the properties of $W(\tau)$ and compare it with welfare under autarky, i.e. the monopoly equilibrium without foreign entry:

$$
U=\frac{3(a-c)^{2}}{8}
$$

\footnotetext{
${ }^{12}$ Derivation is omitted since it is a merely tedious calculation.
} 
where $U$ denotes welfare in autarky. ${ }^{13}$ While this task involves a number of calculations, the main result is simple and interpreted by Figure 2 . This is stated in ${ }^{14}$ :

Proposition Multilateral trade liberalization, i.e. a marginal reduction in tariffs, improves welfare for any initial positive rate of tariffs. However, all countries become worse off under tariff-ridden trade than under no trade, namely, tariff-distorted trade is Pareto inferior to autarky.

Proof. See Figure 2 and Appendix B. ${ }^{15}$

${ }^{13}$ Eq. (10) is obtained from the steady state equations of the following monopoly problem:

$\max _{x} \int_{0}^{\infty} e^{-r t}(a-c-x) x d t$

s.t. $\dot{S}=k S-x$

We see that under autarky the static monopoly output $x=(a-c) / 2$ is an equilibrium output, which allows us to reach (10).

${ }^{14}$ We should note some limitations of comparing steady state welfare. Substituting (4) and (6) into the second threshold in (7), each firm chooses static output for

$$
S \geq \frac{a-c-3 \beta^{*}}{3 \alpha}=\frac{5(a-c)}{9 k}
$$

If both countries are in the autarkic steady state, the resource stock is $(a-c) / 2 k$. Accordingly, starting from this steady state, each firm sets static Cournot outputs just after opening of trade, i.e., $x=y=(a-c) / 3$. Under this choice, $S$ decreases over time and firms switch from static outputs to $x=\alpha S+\beta$ and $y=\alpha S+\beta^{*}$. Our analysis rules out this transition from the autarkic steady state to the trading steady state.

${ }^{15}$ A similar figure can be obtained in static models as well, which is left to Appendix C. 


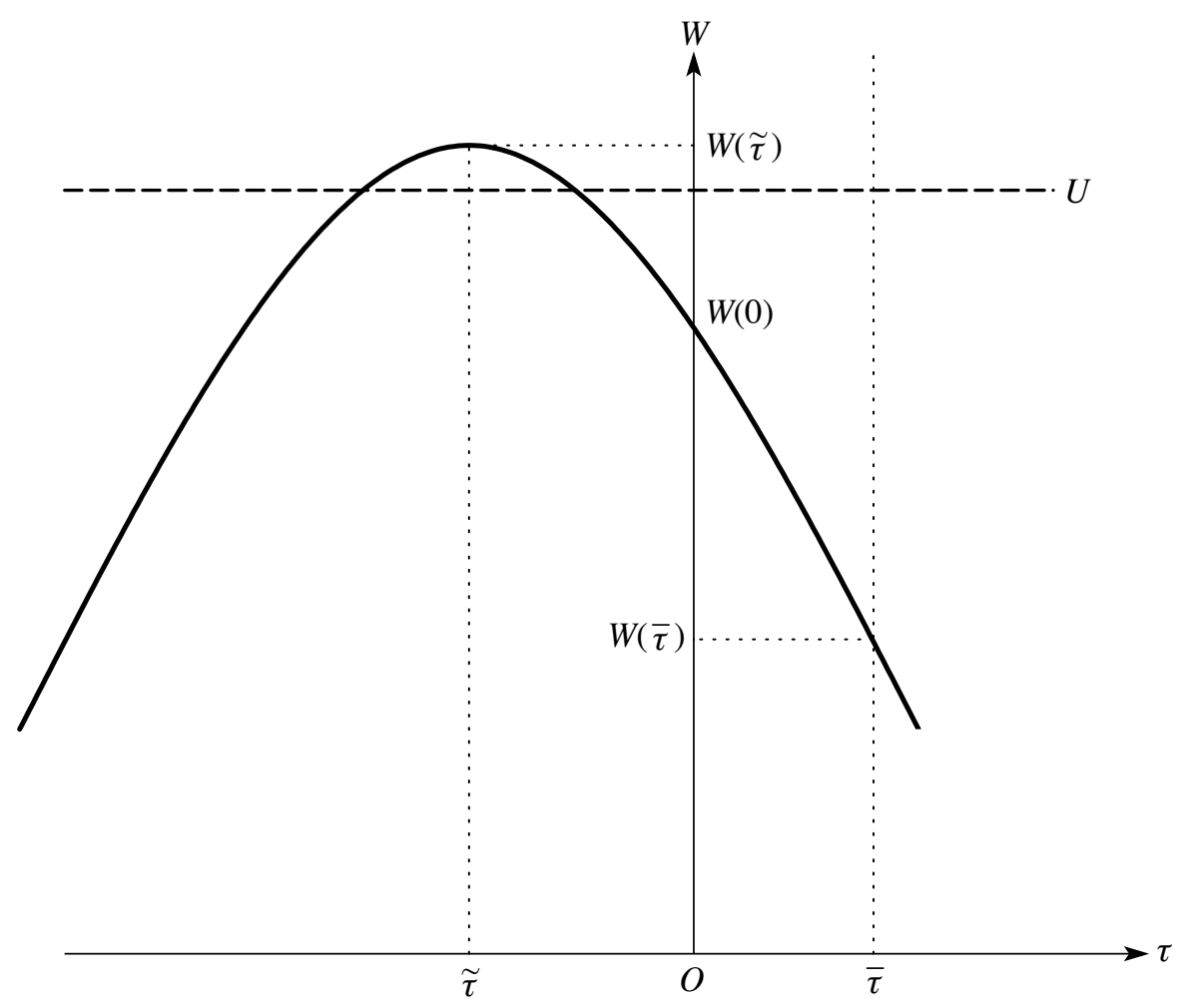

Figure 2: Losses from trade under the feedback strategy

Henceforth, let us interpret this proposition intuitively. We first consider why Pareto inferior trade is possible. A tariff reduction has two effects, which arise in static models as well. On the one hand, it shifts a part of the Home firm's profit to the Foreign firm. This profit-shifting effect reduces the Home welfare. On the other hand, freer trade promotes competition, which has a favorable effect by raising consumer surplus. It is ambiguous whether tariff revenue increases as a result of trade liberalization since it lowers $\tau$ while $y$ increases. In static settings, the positive effects safely dominate the negative effects, which leads to welfare gains as compared to autarky. In other words, welfare monotonically increases with a reduction in $\tau$.

However, another effect arises in our dynamic model, which can be called a closedloop effect through the change in $S$. To understand this better, suppose that the Home firm expands output. This will decrease $S$ by accelerating the resource exploitation. In response to this decrease in $S$, the Foreign firm will decrease output from the fact that the feedback Nash strategy $y(S)=\alpha S+\beta^{*}$ is increasing in $S$. As a result of the Foreign firm's output contraction, $S$ will increase but this is insufficient to offset the first decrease in $S$. Therefore, trade liberalization or allowing foreign entry decreases the steady state level of $S$ and total supply, namely, more trade is anti-competitive. This closed-loop effect causes welfare losses relative to autarky. 
In addition, we should draw attention to the fact that $U \neq W(\bar{\tau})$. The closed-loop effect plays an important role behind this fact as well as the above proposition. As Footnote 13 reports, the static monopoly outcome becomes an autarkic equilibrium. This is because the monopolist's payoff contains no state variable. However, the analogy does not apply to duopoly and each firm's equilibrium strategy becomes dependent on $S$ as in (10). Accordingly, even by evaluating $W(\tau)$ at $\bar{\tau}$, it does not coincide with the autarkic welfare $U$. This is another important but not well-known property the feedback strategy possesses.

Figure 2 convinces us that positive trade gains are possible if both countries adjust import subsidies which are close to $\tilde{\tau}$. However, such a case seems so unrealistic that it is almost impossible to achieve gainful trade.

Our finding reports a relevance of dynamic considerations since it tells us that predictions from static theory no longer survive a dynamic model depending on situations. According to our result, there is a theoretical rationale for anti-globalization: the opening of trade necessarily leads to welfare losses.

\section{Concluding Remarks}

We have clarified that the closed-loop property of feedback strategies in differential games can be a source of losses from trade. Our result suggests that predictions on trade gains based on static models do not always support globalization affirmatively. Once the model is modified to accommodate dynamics, anti-globalization can be reasonable. In this sense, our attempt will be useful in making economic policies on international trade.

Nevertheless, we must recognize that we have resorted to a very specific model, which rests on numerous assumptions. First, we have confined attention to steady states and have not addressed what would happen along the transition path. Second, we have made canonical assumptions such as linear demand and constant marginal cost. Finally, it is more desirable to consider a stagewise game where each country's government non-cooperatively chooses tariffs and then firms play a Cournot game. It is our future research agenda to address these and examine the robustness of the result. 


\section{Appendix}

\section{A. Derivations of Coefficients}

This appendix derives $\alpha, \beta$ and $\beta^{*}$ in (4) and (5). From (3), the first-order conditions for maximizing the right-hand side are

$$
\begin{aligned}
& a-c-2 x-y-V_{S}\left(S, S^{*}\right)=0 \\
& a-c-\tau-2 x^{*}-y^{*}-V_{S^{*}}\left(S, S^{*}\right)=0,
\end{aligned}
$$

where subscripts $S$ and $S^{*}$ represent a partial derivative. Letting $V^{*}\left(S, S^{*}\right)$ be the Foreign firm's value function, the conditions that parallel (11) are obtained:

$$
\begin{aligned}
& a-c-\tau-x-2 y-V_{S}^{*}\left(S, S^{*}\right)=0 \\
& a-c-x^{*}-2 y^{*}-V_{S^{*}}^{*}\left(S, S^{*}\right)=0 .
\end{aligned}
$$

Solving (11) and (12) yields the equilibrium outputs as follows.

$$
\begin{aligned}
& x=\frac{a-c+\tau-2 V_{S}+V_{S}^{*}}{3}, x^{*}=\frac{a-c-2 \tau-2 V_{S^{*}}+V_{S^{*}}^{*}}{3} \\
& y=\frac{a-c-2 \tau+V_{S}-2 V_{S}^{*}}{3}, y^{*}=\frac{a-c+\tau+V_{S^{*}}-2 V_{S^{*}}^{*}}{3}
\end{aligned}
$$

Suppose that each firm's value function is quadratic in the state variables:

$$
\begin{aligned}
& V\left(S, S^{*}\right)=\frac{A}{2} S^{2}+B S+\frac{C}{2} S^{* 2}+D S^{*}+E S S^{*}+F \\
& V^{*}\left(S, S^{*}\right)=\frac{A^{*}}{2} S^{2}+B^{*} S+\frac{C^{*}}{2} S^{* 2}+D^{*} S^{*}+E^{*} S S^{*}+F^{*}
\end{aligned}
$$

from which we have $V_{S}=A S+B+E S^{*}, V_{S^{*}}=C S^{*}+D+E S, V_{S}^{*}=A^{*} S+B^{*}+E^{*} S^{*}$ and $V_{S^{*}}^{*}=C^{*} S^{*}+D+E^{*} S$. Substituting these partial derivatives and (13) into each firm's Hamilton-Jacobi-Bellman equation yields 


$$
\begin{aligned}
& r\left(\frac{A}{2} S^{2}+B S+\frac{C}{2} S^{* 2}+D S^{*}+E S S^{*}+F\right) \\
& =\frac{\left(A+A^{*}\right) S+\left(E+E^{*}\right) S^{*}+B+B^{*}+a-c+\tau}{3} \cdot \frac{\left(-2 A+A^{*}\right) S+\left(-2 E+E^{*}\right) S^{*}-2 B+B^{*}+a-c+\tau}{3} \\
& +\frac{\left(E+E^{*}\right) S+\left(C+C^{*}\right) S^{*}+D+D^{*}+a-c-2 \tau}{3} \cdot \frac{\left(-2 E+E^{*}\right) S+\left(-2 C+C^{*}\right) S^{*}-2 D+D^{*}+a-c-2 \tau}{3} \\
& +\left(A S+E S^{*}+B\right) \frac{\left(3 k+A+A^{*}\right) S+\left(E+E^{*}\right) S^{*}+B+B^{*}-2(a-c)+\tau}{3} \\
& +\left(E S+C S^{*}+D\right) \frac{\left(E+E^{*}\right) S+\left(3 k+C+C^{*}\right) S^{*}+D+D^{*}-2(a-c)+\tau}{3} \\
& \mathrm{r}\left(\frac{A^{*}}{2} S^{2}+B^{*} S+\frac{C^{*}}{2} S^{* 2}+D^{*} S^{*}+E^{*} S S^{*}+F^{*}\right) \\
& =\frac{\left(A+A^{*}\right) S+\left(E+E^{*}\right) S^{*}+B+B^{*}+a-c-2 \tau}{3} \cdot \frac{\left(A-2 A^{*}\right) S+\left(E-2 E^{*}\right) S^{*}+B-2 B^{*}+a-c-2 \tau}{3} \\
& +\frac{\left(E+E^{*}\right) S+\left(C+C^{*}\right) S^{*}+D+D^{*}+a-c+\tau}{3} \cdot \frac{\left(E-2 E^{*}\right) S+\left(C-2 C^{*}\right) S^{*}+D-2 D^{*}+a-c+\tau}{3} \\
& +\left(A^{*} S+E^{*} S^{*}+B^{*}\right) \frac{\left(3 k+A+A^{*}\right) S+\left(E+E^{*}\right) S^{*}+B+B^{*}-2(a-c)+\tau}{3} \\
& +\left(E^{*} S+C^{*} S^{*}+D^{*}\right) \frac{\left(E+E^{*}\right) S+\left(3 k+C+C^{*}\right) S^{*}+D+D^{*}-2(a-c)+\tau}{3} .
\end{aligned}
$$

Each coefficient is obtained as follows. First, we immediately have the following system of equations by equating the terms multiplied by $S^{2}$.

$$
\begin{aligned}
& \frac{r A}{2}=\frac{\left(A+A^{*}\right)\left(-2 A+A^{*}\right)}{9}+\frac{\left(E+E^{*}\right)\left(-2 E+E^{*}\right)}{9}+\frac{A\left(3 k+A+A^{*}\right)}{3}+\frac{E\left(E+E^{*}\right)}{3} \\
& \frac{r A^{*}}{2}=\frac{\left(A+A^{*}\right)\left(A-2 A^{*}\right)}{9}+\frac{\left(E+E^{*}\right)\left(E-2 E^{*}\right)}{9}+\frac{A^{*}\left(3 k+A+A^{*}\right)}{3}+\frac{E^{*}\left(E+E^{*}\right)}{3} .
\end{aligned}
$$

Subtracting the second equation from the first equation and rearranging terms yield

$$
\left(\frac{r}{2}-k\right)\left(A-A^{*}\right)=0,
$$


from which we have $A=A^{*}$. Applying the same procedure to the terms multiplied by $S^{* 2}$ gives $C=C^{*}$. Further substitution of these results into the terms multiplied by $S S^{*}$ and rearranging the resulting expressions, we reach that $E=E^{*}=0$. Accordingly, the value functions turn to be separable in $S$ and $S^{*}$. Moreover, applying $A=A^{*}, C=C^{*}$ and $E=E^{*}=0$ in the coefficients attached to $S^{2}$ and $S^{2^{*}}$, we finally get $A=C=0,-9(2 k-r) / 8$. Note that $A=C=0$ yields static Cournot outputs.

The other coefficients are now computed. $B$ and $B^{*}$ (resp. $D$ and $D^{*}$ ) are the solutions to the system of equations obtained by setting the terms multiplied by $S$ (resp. $S^{*}$ ) to zero. Solving the system yields

$$
\begin{aligned}
& B=D^{*}=\frac{A[15(k-r)(a-c)-4(A+3 k-3 r) \tau]}{3(k-r)(8 A+9 k-9 r)} \\
& B^{*}=D=\frac{A[15(k-r)(a-c)+(4 A-3 k+3 r) \tau]}{3(k-r)(8 A+9 k-9 r)} .
\end{aligned}
$$

When $A=-9(2 k-r) / 8$, these coefficients are further rewritten as

$$
\begin{aligned}
& B=D^{*}=\frac{(2 k-r)[10(k-r)(a-c)-(2 k-5 r) \tau]}{16 k(k-r)} \\
& B^{*}=D=\frac{(2 k-r)[10(k-r)(a-c)-(8 k-5 r) \tau]}{16 k(k-r)}
\end{aligned}
$$

Substituting these results into $x, x^{*}, y$ and $y^{*}$, the explicit form of (interior) feedback strategies is derived as follows.

$$
\begin{aligned}
& x=\frac{-A S-2 B+B^{*}+a-c+\tau}{3} \equiv \alpha S+\beta \\
& y=\frac{-A S+B-2 B^{*}+a-c-2 \tau}{3} \equiv \alpha S+\beta^{*}
\end{aligned}
$$

where $\alpha, \beta$ and $\beta^{*}$ are given by (4) and (6). Analogously, we have $x^{*}=\alpha S^{*}+\beta$ and $y^{*}=\alpha S^{*}+\beta$.

\section{B. Properties of $W(\tau)$}

This appendix proves some of the key properties of $W(\tau)$ in Figure 2. Let us begin by comparing welfare under free trade with $\tau=0$ and welfare under autarky (10). Setting $\tau=0$ in (9), we have 


$$
W(0)=\frac{(2 k-5 r)(10 k-13 r)(a-c)^{2}}{18(2 k-3 r)^{2}} .
$$

Taking the ratio between $W(0)$ and $U$ yields

$$
\frac{W(0)}{U}=\frac{4(2 k-5 r)(10 k-13 r)}{27(2 k-3 r)^{2}} .
$$

We easily see that this is less than one since subtracting the denominator from the numerator equals $-(2 k+3)(14 k-17 r)<0$. Therefore, autarky is Pareto superior to free trade.

We proceed to computing welfare under the prohibitive tariff and compare it with welfare under autarky. The prohibitive tariff denoted by $\bar{\tau}$ is obtained by setting $y=0$ in (7) and has an explicit form

$$
\bar{\tau}=\frac{8(k-r)(a-c)}{10 k-13 r} .
$$

Note that $W(\bar{\tau}) \neq U$ under the feedback strategy so that we cannot regard $W(\bar{\tau})$ as an autarkic level of welfare. ${ }^{16}$ Substituting $\bar{\tau}$ into (9), $W(\bar{\tau})$ becomes

$$
W(\bar{\tau})=\frac{3(2 k-5 r)(6 k-7 r)(a-c)^{2}}{2(10 k-13 r)^{2}} .
$$

Let us take the ratio between $W(\bar{\tau})$ and $U$ :

$$
\frac{W(\bar{\tau})}{U}=\frac{4(2 k-5 r)(5 k-7 r)}{(10 k-13 r)^{2}} .
$$

Subtracting the denominator from the numerator yields

$$
\begin{aligned}
& 4(2 k-5 r)(6 k-7 r)-(10 k-13 r)^{2} \\
& =-52 k^{2}+204 r k-29 r^{2}
\end{aligned}
$$

which is negative for any $k$ and $r$.

When we compare $W(0)$ and $W(\bar{\tau})$, we see that

$$
\frac{W(0)}{W(\bar{\tau})}=\frac{(10 k-13 r)^{3}}{27(6 k-7 r)(2 k-3 r)^{2}},
$$

\footnotetext{
${ }^{16}$ It is easy to check that $W(\bar{\tau})=U$ under static Cournot outputs.
} 
which proves to be larger than one since the difference between the numerator and the denominator is

$$
\begin{aligned}
& (10 k-13 r)^{3}-27(2 k-3 r)^{2}(6 k-7 r) \\
& =8(2 k-3 r)^{3}+(6 k-7 r)^{3}+3(2 k+r)(2 k-3 r)(6 k-7 r)>0 .
\end{aligned}
$$

Comparing $W(0), W(\bar{\tau})$ and $U$, we have the ranking of $U>W(0)>W(\bar{\tau})$ as is depicted in Figure 2. As a result, we have confirmed that welfare under any positive level of tariff is below $U$.

Our next task is to know how $W(\tau)$ depends on $\tau$ globally. To see this, let us derive the first and second derivatives of (9) with respect to $\tau$ :

$$
\begin{aligned}
& W^{\prime}(\tau)=\frac{-(2 k-5 r)[(2 k-5 r) \tau+8(k-r)(a-c)]}{36(2 k-3 r)^{2}} \\
& W^{\prime \prime}(\tau)=\frac{-(2 k-5 r)^{2}}{36(2 k-3 r)^{2}}<0 .
\end{aligned}
$$

These imply that $W(\tau)$ is strictly concave in $\tau$ and reaches a maximum when $\tau$ takes $\tilde{\tau}=-8(k-r)(a-c) /(2 k-5 r)<0$ Substituting this into $W(\tau)$, the maximum welfare is computed as

$$
W(\tilde{\tau})=\frac{(a-c)^{2}}{2}
$$

Consequently, it follows that $W(\tilde{\tau})>U$ by comparing $W(\tilde{\tau})$ and (10). This allows us to draw the locus of $W(\tau)$ as in Figure 2. In other words, if both countries choose $\tilde{\tau}$, they gain from trade.

\section{Static Cournot Outcomes}

This appendix briefly addresses what consequences follow if static Cournot outputs were to be chosen. Since this is a simple routine, we sketch only the core result. Static Cournot outputs are

$$
x=\frac{a-c+\tau}{3}, y=\frac{a-c-2 \tau}{3} .
$$

Substituting these into (9), a country's welfare depends on $\tau$ as follows.

$$
W_{M}(\tau)=\frac{-\tau^{2}-2(a-c) \tau+8(a-c)^{2}}{18},
$$


where subscript $M$ indicates the case of myopic behavior of firms.

Differentiating (15) with respect to $\tau$, we obtain

$$
W_{M}^{\prime}(\tau)=\frac{-(\tau+a-c)}{9}, W_{M}^{\prime \prime}(\tau)=\frac{-1}{9}
$$

which enables us to know that $\mathrm{W}_{\mathrm{M}}{ }^{\prime}(\tau)$ is strictly concave and $\tilde{\tau}=-(a-c)<0$ yields its maximum. The resulting maximum welfare is explicitly given by

$$
W_{M}(\tilde{\tau})=\frac{(a-c)^{2}}{2},
$$

which is larger than both the free trade welfare $W_{M}(0)=4(a-c)^{2} / 9$ and the autarkic welfare $U=3(a-c)^{2} / 8$. As a result, the dependence of $W$ on $\tau$ in the static case is depicted as Figure 3.

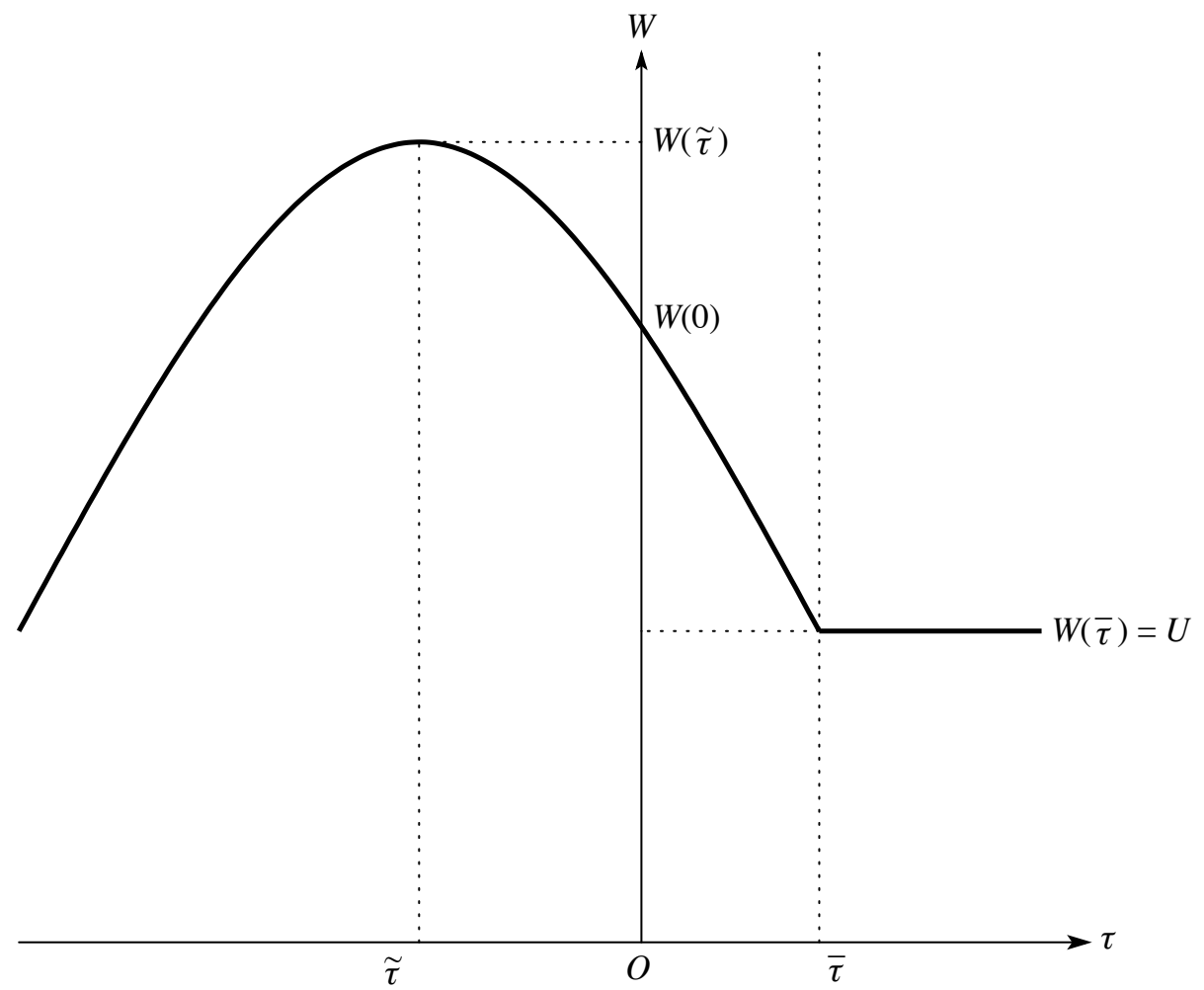

Figure 3: Static Cournot outcome 


\section{References}

Benchekroun, H., 2003, "Unilateral Production Restrictions in a Dynamic Duopoly", Journal of Economic Theory, 111, 214-239.

Benchekroun, H., 2008, "Comparative Dynamics in a Productive Asset Oligopoly", Journal of Economic Theory, 138, 237-261.

Benchekroun, H. and N. V. Long, 2002, “Transboundary Fishery: A Differential Game Model", Economica, 69, 207-221.

Brander, J. A., 1981, “Intra-Industry Trade in Identical Commodities”, Journal of International Economics, 11, 1-14.

Brander, J. A. and P. R. Krugman, 1983, “A 'Reciprocal Dumping' Model of International Trade”, Journal of International Economics, 15, 313-321.

Brander, J. A. and B. J. Spencer, 1984, "Tariff Protection and Imperfect Competition”, in H. Kierzkowski (ed.), Monopolistic Competition and International Trade, (Oxford: Oxford University Press), 194-206.

Dockner, E. J. and N. V. Long, 1993, "International Pollution Control: Cooperative versus Noncooperative Strategies”, Journal of Environmental Economics and Management, 25, 13-29.

Dockner, E. J., S. Jorgensen, N. V. Long and G. Sorger, 2000, Differential Games in Economics and Management Science (Cambridge: Cambridge University Press).

Fujiwara, K., 2009, "Detrimental Trade Liberalization in a Dynamic Duopoly”, Mimeo., Kwansei Gakuin University.

Helpman, E. and P. R. Krugman, 1985, Market Structure and Foreign Trade (Cambridge: MIT Press).

Kemp, M. C., 1995, The Gains from Trade and the Gains from Aid: Essays in International Trade Theory (London: Routledge).

Kemp, M. C. and N. V. Long, 1979, “The Under-Exploitation of Natural Resources: A Model with Overlapping Generations", Economic Record, 55, 214-221.

Lohoues, H., 2006, “Asymmetries in a Common Pool Natural Resource Oligopoly”, Mimeo., University of Montreal.

Markusen, J. R., 1981, "Trade and the Gains from Trade with Imperfect Competition," Journal of International Economics, 11, 531-551.

Newbery, D. M. G. and J. E. Stiglitz, 1984, "Pareto Inferior Trade", Review of Economic Studies, 51, 1-12.

Shimomura, K., 1991, "The Feedback Equilibria of a Differential Game of Capitalism”, Journal of Economic Dynamics and Control, 15, 317-338.

Shy, O., 1988, “A General Equilibrium Model of Pareto Inferior Trade”, Journal of International Economics, 25, 143-154.

Tsutsui, S. and K. Mino, 1990, "Nonlinear Strategies in Dynamic Duopolistic Competition with Sticky Prices”, Journal of Economic Theory, 52, 136-161.

Wong, K., 1995, International Trade in Goods and Factor Mobility (Cambridge: MIT Press). 